\title{
Hydrogen Reduction of Ferric Ions for Use in Copper Electrowinning
}

Karl S. Noah

Debby F. Bruhn

John E. Wey

Robert S. Cherry

January 2005

Idaho National Engineering and Environmental Laboratory Bechtel BWXT Idaho, LLC 


\title{
Hydrogen Reduction of Ferric lons for Use in Copper Electrowinning
}

\author{
Karl S. Noah \\ Debby F. Bruhn \\ John E. Wey \\ Robert S. Cherry
}

January 2005

Idaho National Engineering and Environmental Laboratory Idaho Falls, Idaho 83415

Prepared for the U.S. Department of Energy

Under DOE Idaho Operations Office

Contract DE-AC07-99ID13727 


\begin{abstract}
The conventional copper electrowinning process uses the water hydrolysis reaction as the anodic source of electrons. However this reaction generates acid mist and requires large quantities of energy. In order to improve energy efficiency and avoid acid mist, an alternative anodic reaction of ferrous ion oxidation has been proposed. This reaction does not involve evolution of acid mist and can be carried out at a lower cell voltage than the conventional process. However, because ferrous ions are converted to ferric ions at the anode in this process, there is a need for reduction of ferric ions to ferrous ions to continue this process. The most promising method for this reduction is the use of hydrogen gas since the resulting byproduct acid can be used elsewhere in the process and, unlike other reductants, hydrogen does not introduce other species that need subsequent removal.
\end{abstract}

Because the hydrogen reduction technology has undergone only preliminary lab scale testing, additional research is needed to evaluate its commercial potential. Two issues for this research are the potentially low mass transfer rate of hydrogen into the electrolyte stream because of its low solubility in water, and whether other gaseous reductants less expensive than hydrogen, such as natural gas or syngas, might work. In this study various reductants were investigated to carry out the reduction of ferric ions to ferrous ions using a simulated electrolyte solution recycled through a trickle bed reactor packed with catalyst. The gases tested as reductants were hydrogen, methane, carbon monoxide, and a 50/50 mixture of $\mathrm{H}_{2}$ and CO. Nitrogen was also tested as an inert control. These gases were tested because they are constituents in either natural gas or syngas. The catalysts tested were palladium and platinum. Two gas flow rates and five electrolyte flow rates were tested.

Pure hydrogen was an effective reductant of ferric ion. The rates were similar with both palladium and platinum. The ferric iron reduction increased with both the flow rate of gas as well as the liquid flow rate (up to $\sim 0.1 \mathrm{~g} / \mathrm{L} / \mathrm{min}$ ). Pure carbon monoxide also reduced the ferric ion, but at a rate about one tenth that of pure hydrogen at similar conditions. The syngas mixture of equimolar hydrogen and carbon monoxide reacted at a rate intermediate between each gas as a pure stream (up to $\sim 0.06 \mathrm{~g} / \mathrm{L} / \mathrm{min}$ ). This gas mixture shows that some form of unpurified reformer gas could be used to reduce the ferric ion in the electrolyte solution. Nitrogen was inert causing very little to no reduction of ferric ion. 


\section{CONTENTS}

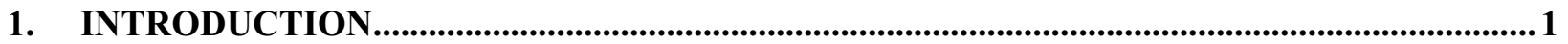

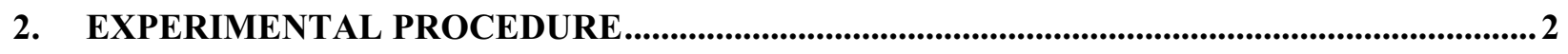

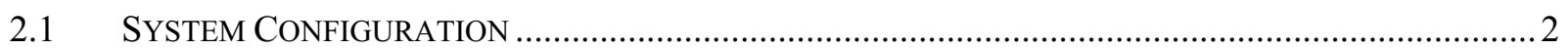



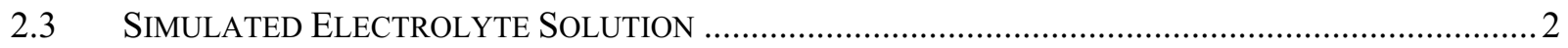

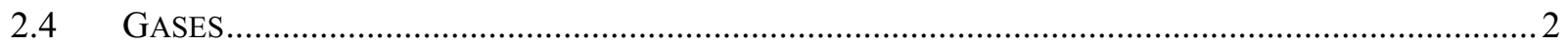

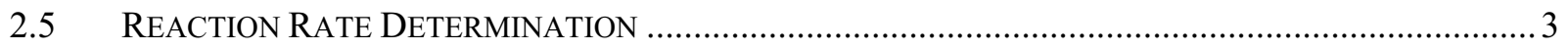

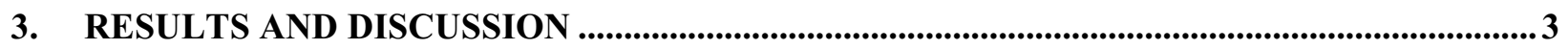

3.1 RELATIVE RATES OF REACTION AND MASS TRANSFER........................................................ 3

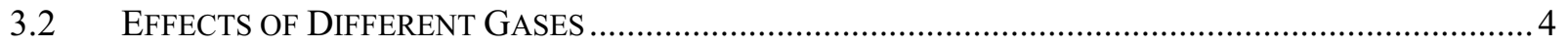

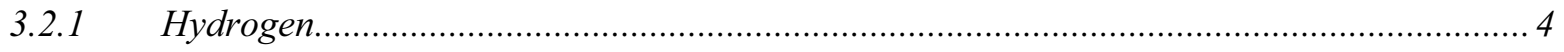

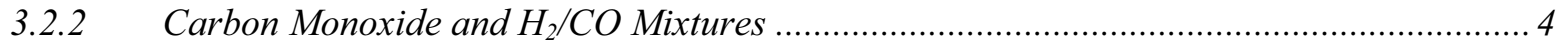

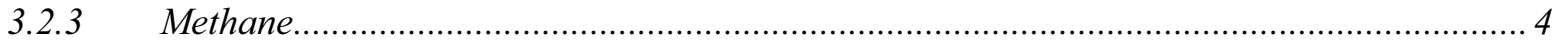

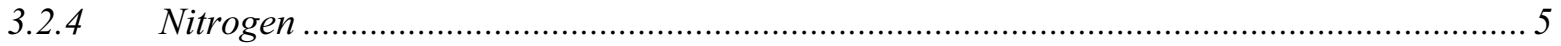

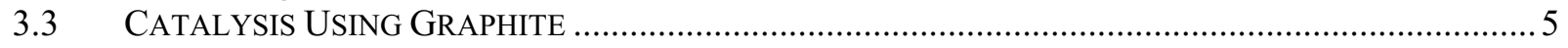

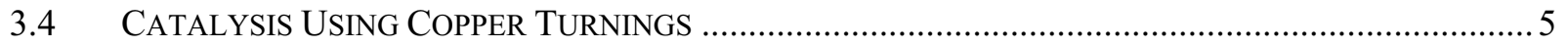

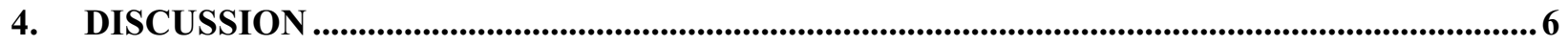

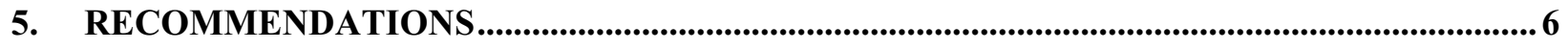

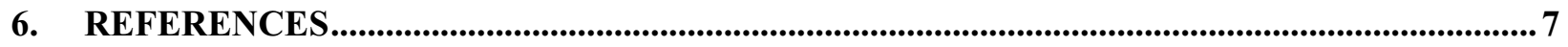

Figures and Tables

Figure 1 Schematic of Trickle Bed Setup $\quad 8$

Figure 2 Standard Curve for Ferric Ion Concentration vs Absorbance at $400 \mathrm{~nm} \quad 8$

Figure 3 Hydrogen on Palladium 9

Figure 4 Hydrogen on Platinum $\quad 9$

Figure 5 Carbon Monoxide on Palladium 10

Figure 6 Carbon Monoxide on Platinum 10

Figure 7 Hydrogen/Carbon Monoxide on Palladium 11

Figure 8 Hydrogen/Carbon Monoxide on Platinum 11

Figure 9 Methane on Palladium $\quad 12$

Figure 10 Methane on Platinum $\quad 12$

Figure 11 Nitrogen on Palladium $\quad 13$

Figure 12 Nitrogen on Platinum 13

Table 1 Ferric Ion Reduction Rates 14 


\section{ACRONYMS}

\begin{tabular}{|c|c|}
\hline $\mathrm{Cl}^{-}$ & chloride ion \\
\hline $\mathrm{CO}$ & carbon monoxide \\
\hline $\mathrm{Cu}^{+2}$ & copper ion \\
\hline $\mathrm{CuSO}_{4} \cdot 5 \mathrm{H}_{2} \mathrm{O}$ & cupric sulfate \\
\hline $\mathrm{Fe}^{+2}$ & ferrous iron \\
\hline $\mathrm{Fe}^{+3}$ & ferric iron \\
\hline $\mathrm{FeSO}_{4} \cdot 7 \mathrm{H}_{2} \mathrm{O}$ & ferrous sulfate \\
\hline $\mathrm{Fe}_{2}\left(\mathrm{SO}_{4}\right)_{3} \cdot 4 \mathrm{H}_{2} \mathrm{O}$ & ferric sulfate \\
\hline $\mathrm{g}$ & gram \\
\hline $\mathrm{g} / \mathrm{L}$ & grams per liter \\
\hline $\mathrm{g} / \mathrm{L} / \mathrm{min}$ & gram per liter per minute \\
\hline $\mathrm{H}^{+}$ & hydrogen ion \\
\hline $\mathrm{H}_{2}$ & hydrogen gas \\
\hline $\mathrm{H}_{2} \mathrm{SO}_{4}$ & sulfuric acid \\
\hline INEEL & Idaho National Engineering and Environmental Laboratory \\
\hline $\mathrm{L}$ & liter \\
\hline $\mathrm{Mg}^{+2}$ & magnesium ion \\
\hline $\mathrm{MgCl}_{2} \cdot 6 \mathrm{H}_{2} \mathrm{O}$ & magnesium chloride \\
\hline $\mathrm{MgSO}_{4} \cdot 7 \mathrm{H}_{2} \mathrm{O}$ & magnesium sulfate \\
\hline $\mathrm{mg}$ & milligrams \\
\hline $\mathrm{mg} / \mathrm{L}$ & milligrams per liter \\
\hline $\min$ & minute \\
\hline $\mathrm{ml}$ & milliliter \\
\hline $\mathrm{Mn}^{+2}$ & manganese ion \\
\hline $\mathrm{MnSO}_{4} \cdot \mathrm{H}_{2} \mathrm{O}$ & manganese sulfate \\
\hline $\mathrm{N}_{2}$ & nitrogen \\
\hline $\mathrm{nm}$ & nanometer \\
\hline $\mathrm{Pd}$ & palladium \\
\hline $\mathrm{PdCl}_{2}$ & palladium chloride \\
\hline PS & pump speed \\
\hline $\mathrm{Pt}$ & platinum \\
\hline ppm & parts per million \\
\hline RR & rotameter reading \\
\hline $\mathrm{SO}_{4}^{-2}$ & sulfate ion \\
\hline $\mathrm{v} / \mathrm{v}$ & volume per volume \\
\hline vol & volume \\
\hline wt & weight \\
\hline
\end{tabular}




\section{INTRODUCTION}

The traditional technology for copper electrowinning - water hydrolysis as the anodic source of electrons to reduce copper ions to metal-requires large quantities of energy. New technology utilizing ferrous oxidation in place of water decomposition potentially halves the energy requirement. To allow recycling of the iron redox agent in this process, the ferric ions generated by reaction with copper ions must be chemically reduced back to ferrous ions. A promising method for this reduction is the use of hydrogen gas since the resulting byproduct acid can be used elsewhere in the ore refining process and, unlike other reductants, hydrogen does not introduce other species that need subsequent removal. The overall reactions involving hydrogen, copper, and iron are then:

$$
\begin{aligned}
& \text { Copper reduction: } \quad \mathrm{Cu}^{+2}+2 \mathrm{Fe}^{+2} \rightarrow \mathrm{Cu}^{0}+2 \mathrm{Fe}^{+3} \\
& \text { Ferric reduction: } \quad \mathrm{H}_{2}+2 \mathrm{Fe}^{+3} \rightarrow 2 \mathrm{Fe}^{+2}+2 \mathrm{H}^{+} \\
& \text {Net reaction: } \quad \mathrm{H}_{2}+\mathrm{Cu}^{+2} \rightarrow \mathrm{Cu}^{0}+2 \mathrm{H}^{+}
\end{aligned}
$$

The anion in this system is primarily sulfate, resulting from the air oxidation and dissolution of copper sulfide minerals in the ore. The net reaction generates hydrogen ions which are used to dissolve more copper from the ore.

Because the hydrogen reduction technology has undergone only preliminary lab scale testing, additional data is needed to evaluate its commercial potential. Several problems stand out immediately. One is the potentially low mass transfer rate of hydrogen into the electrolyte stream because of its low solubility in water. In this work, a trickle bed reactor was evaluated because of their good gas-liquid contacting, low energy requirements, scalability, and extensive experience base in other industries particularly wastewater treatment. Trickle beds are a packed bed of catalyst particles with the interparticle space primarily filled with a gas containing one of the reactants. Liquid flows at a modest rate over the catalyst particles, giving good mass transfer through a combination of a large amount of surface area in contact with the gas phase and turbulent mixing in the liquid phase to help transfer dissolved gas to the catalyst surface.

The second concern with hydrogen reduction is identifying an effective catalyst for the reaction. Previous work has shown that graphite or platinum catalysts $(1,2)$ speed the reaction rate. However, that research used a gas of $2 \mathrm{vol} \%$ hydrogen in argon at atmospheric pressure. Such a low partial pressure of hydrogen would hinder both mass transfer and reaction rates. Any practical hydrogen source would naturally provide much higher concentrations of the reductant. A range of catalysts needs to be tested at reaction conditions closer to what would be used in practice. This work tested graphite alone and carbon support material impregnated with platinum or palladium.

A third issue is whether other gaseous reductants less expensive than hydrogen might work. One generally available candidate is natural gas, a mixture predominately containing methane with up to about $10 \%$ total of nitrogen, carbon dioxide, ethane, and propane in varying ratios depending on the source of the gas. Because methane is a relatively unreactive molecule, an alternative is to convert the natural gas into a mixture of hydrogen and carbon monoxide usually called synthesis gas, or syngas for short. This mixture of $10-50 \%$ hydrogen, similar amounts of carbon monoxide, and various inert gases can be made from any of a number of carbon-containing materials such as biomass, coal, natural gas, or petroleum products. Use of syngas for copper reduction has the dual advantage of not requiring any purification of the hydrogen while providing a second potential reactant, carbon monoxide. 
Based on guidance provided by the client, the experimental conditions were constrained in two ways. The reaction temperature is $50^{\circ} \mathrm{C}$, fixed by pilot plant and full-scale electrowinning circuits. In addition, the composition of the ferric-containing electrolyte solution is fixed at values provided by the client.

\section{EXPERIMENTAL PROCEDURE}

\subsection{System Configuration}

The clear plastic trickle bed reactor was 2.5 " diameter by 7" tall packed with approximately $128 \mathrm{~g}$ $(\sim 5.25 ")$ of catalyst (Figure 1). On each end of the catalyst bed, about $60 \mathrm{~g}$ of Teflon boiling stones helped distribute or collect liquid more evenly. Once assembled, each catalyst bed was not disturbed so any effects of the way it was packed would remain constant across all the runs with that material.

A peristaltic pump circulated one liter of electrolyte solution to the top of the reactor from a reservoir kept at $50{ }^{\circ} \mathrm{C}$ by a heating mantle. The liquid drained by gravity through the bed and into the reservoir directly below the reactor. The electrolyte was circulated at flow rates of 17, 34, 67, 140, or $204 \mathrm{ml} / \mathrm{min}$ (labeled PS - pump speed - on the graphs), with the highest value being the point at which the reactor flooded. The gaseous reductant was introduced to the bed through a small tube terminating on the reactor axis in the lower layer of boiling stones. The gas flowed upward through the bed and vented through an exit tube located in the upper layer of boiling stones. The gas flow was either $37 \mathrm{ml} / \mathrm{min}$ or $176 \mathrm{ml} / \mathrm{min}$ (labeled RR - rotameter reading - on the graphs). Not all combinations of gas flow and liquid flow were used with all gases.

\subsection{Catalysts}

The two primary catalysts tested were 4-8 mesh carbon impregnated with $0.5 \mathrm{wt} \%$ platinum or $1.0 \mathrm{wt} \%$ palladium, both from Aldrich Chemical Company. Copper turnings (J.T. Baker Cat. No. 1-1732) were briefly tested to see if they might work with hydrogen to reduce ferric ion to the ferrous form at the conditions of this system. To parallel previous work $(1,2)$, graphite was also tested. The $99.9995 \%$ pure graphite came from $1 / 4$ " diameter graphite rod cut into $1 / 4$ " long sections. This rod was not intended for use as a catalyst but as a high purity electrode for electrochemical cells and therefore would be expected to have a relatively low surface area.

\subsection{Simulated Electrolyte Solution}

The initial concentration of the simulated electrolyte solution used for this study consisted of $38 \mathrm{~g} / \mathrm{L} \mathrm{Cu}^{+2}$, $28.5 \mathrm{~g} / \mathrm{L} \mathrm{Fe}^{+2}, 1.5 \mathrm{~g} / \mathrm{L} \mathrm{Fe}^{+3}, 0.088 \mathrm{~g} / \mathrm{L} \mathrm{Mn}^{+2}, 0.88 \mathrm{~g} / \mathrm{L} \mathrm{Mg}^{+2}, 0.15 \mathrm{~g} / \mathrm{L} \mathrm{Cl}^{-}$, and $271.0 \mathrm{~g} / \mathrm{L} \mathrm{SO}_{4}{ }^{-2}$. The simulated electrolyte solution was made by adding $149.3 \mathrm{~g} \mathrm{CuSO}_{4} \cdot 5 \mathrm{H}_{2} \mathrm{O}, 141.9 \mathrm{~g} \mathrm{FeSO} \cdot 7 \mathrm{H}_{2} \mathrm{O}, 6.3 \mathrm{~g}$ $\mathrm{Fe}_{2}\left(\mathrm{SO}_{4}\right)_{3} \cdot 4 \mathrm{H}_{2} \mathrm{O}, 8.9 \mathrm{~g} \mathrm{MgSO}_{4} \cdot 7 \mathrm{H}_{2} \mathrm{O}, 0.27 \mathrm{~g} \mathrm{MnSO}_{4} \cdot \mathrm{H}_{2} \mathrm{O}, 0.04 \mathrm{~g} \mathrm{MgCl}_{2} \cdot 6 \mathrm{H}_{2} \mathrm{O}$, and $87 \mathrm{~mL}$ concentrated $(36 \mathrm{~N}) \mathrm{H}_{2} \mathrm{SO}_{4}$ to deionized water and bringing the volume to $1 \mathrm{~L}$. The initial $\mathrm{pH}$ was around 0.40 and was not adjusted further.

\subsection{Gases}

The gases tested as reductants were hydrogen, methane (as the major component of natural gas), carbon monoxide, and a 50/50 mixture of $\mathrm{H}_{2}$ and $\mathrm{CO}$ as a representative syngas. All gases came from pressurized gas cylinders at least at $99.99 \%$ purity. The $\mathrm{H}_{2} / \mathrm{CO}$ mixture was blended from the two pure gases using a mixing rotameter. Nitrogen was also tested as an inert control. 


\subsection{Reaction Rate Determination}

The electrolyte solution in the heated reservoir was sampled at intervals to measure its absorbance at 400 $\mathrm{nm}$ on a spectrophotometer. This data was then converted to ferric ion concentration using a linear standard curve. The reduction rate $(\mathrm{g} / \mathrm{L} / \mathrm{min})$ was determined from the initial rate of decrease of ferric ion concentration with time.

To prepare the standard curve, a blank and several standard ferric solutions were made using the initial electrolyte solution recipe. The blank contained all the cations except $\mathrm{Cu}^{+2}, \mathrm{Fe}^{+2}$, and $\mathrm{Fe}^{+3}$. The standard ferric solutions contained all cations plus $\mathrm{Fe}_{2}\left(\mathrm{SO}_{4}\right)_{3} \cdot 4 \mathrm{H}_{2} \mathrm{O}$ to yield known concentrations of $\mathrm{Fe}^{+3}$. The spectrophotometer was zeroed using the blank. The blank plus $38 \mathrm{~g} / \mathrm{L} \mathrm{Cu}^{+2}$ (same as the electrolyte) was then read to ensure there was no interference by copper. It read 0.000 to 0.003 . Absorbance was proportional to ferric ion concentration over the range used (Figure 2).

\section{RESULTS AND DISCUSSION}

\subsection{Relative Rates of Reaction and Mass Transfer}

To determine whether the reaction rates measured in this system were limited by mass transfer of reductant into the liquid phase or by the kinetics of reaction on the catalyst surface, reaction rates at several flow conditions were compared. Control conditions were tested for two hours each with the reactor packed only with Teflon boiling stones. In the absence of a catalyst, no ferric ion reduction was seen for any of several combinations of hydrogen and electrolyte flow rates. Figure 3 shows the conversion of ferric ion when using the palladium catalyst and hydrogen gas at various gas and liquid flow rates. While the rate of ferric reduction was not affected by the flow rate of hydrogen gas, it increased significantly with the liquid flow rate up to the maximum liquid flow rate achievable in this system.

This result indicates that the reaction rate in this system is limited by the mass transfer rate of hydrogen gas into the liquid phase. If the catalyst kinetics were controlling, increasing the achievable mass transfer rate by increasing liquid flow would not have increased the measured rate of ferric ion reduction. This conclusion is confirmed by the gas and liquid flow results. In gas-liquid mass transfer, the resistance is predominately on the liquid side of the interface because of the much lower diffusion rates in liquids as compared to gases. Increasing the gas velocity does little to improve diffusion into the liquid from the gas-liquid interface, which will be saturated with the gaseous species. A higher liquid velocity, however, increases turbulence in the liquid and mixing in the irregular voids between catalyst particles, increasing the advective transport of dissolved gas from the interface to the bulk liquid and from there to the catalyst surface.

In fact, if the gas phase is a pure component then its velocity makes no difference as long as it is not so large that it affects the liquid flow pattern. Only if the gaseous reactant is a partial component of the gas mixture can there possibly be a diffusional limitation on the gas side that would be improved by more gas velocity. This was likely a problem with the $2 \%$ hydrogen mixture used in earlier work. It is worth noting though that increasing the partial pressure of the reductant gas component, whether by increasing its fraction in a mixture and/or by increasing the total gas pressure, would improve mass transfer rates by increasing the dissolved gas concentration at the liquid interface. 


\subsection{Effects of Different Gases}

\subsubsection{Hydrogen}

Pure hydrogen was an effective reductant of ferric ion (Figures 3-4, Table 1). The rates were similar with both the palladium and platinum catalysts, as would be expected if mass transfer of hydrogen gas was the main rate limitation in this system. Unusually, the ferric ion reduction rate increased with both the flow rate of gas as well as the liquid flow rate. With a pure gas, there should be no effect of its velocity, only its pressure. The effect might be an indirect one if these higher gas flow rates affected the holdup or flow pattern of the liquid as it flowed over the catalyst particles.

Analysis of these results after experiments ended some indication of interfering reactions. The runs of hydrogen with palladium were followed by runs with nitrogen, which should have had no reaction. However, the first few nitrogen runs showed a decreasing amount of ferric ion reduction (see Figure 11). This was attributed to reaction of absorbed hydrogen carried over from the previous set of runs. The third of those runs actually showed an increase in the absorbance. This could have been caused by oxidation of ferrous ions by either air introduced to the reactor between runs or by the sulfate ions in this system. Sulfuric acid is well known as a strong oxidizing agent. The possibility of these reactions was not recognized in the design of the experiments and was not explored in them.

During the early experiments it was found that filling the reactor twice with a concentrated acid solution (174 $\mathrm{ml}$ concentrated $\mathrm{H}_{2} \mathrm{SO}_{4}$ to $2 \mathrm{~L}$ deionized water) for 20 minutes caused the following run with nitrogen to have a smaller decrease in absorbance, which was interpreted at the time as removal of absorbed hydrogen from the carbon catalyst. In addition, the spent acid from the wash was colored slightly blue-green, indicating that copper and/or iron was being rinsed or leached from the catalyst particles. This acid wash was used on all following runs with any gas.

\subsubsection{Carbon Monoxide and $\mathrm{H}_{2} / \mathrm{CO}$ Mixtures}

Pure carbon monoxide also worked to reduce ferric ion, although the rate with $\mathrm{CO}$ was about one tenth as much as with hydrogen under similar conditions (Figures 5-6, Table 1). The rate was somewhat faster with platinum catalyst and was affected by liquid flow rates only mildly (palladium) or not at all (platinum). These results indicate that the rate-limiting factor in these runs was the kinetics of $\mathrm{CO}$ oxidation on the catalyst.

The syngas mixture of equimolar hydrogen and carbon monoxide reacted at a rate intermediate between each gas as a pure stream (Figures 7 and 8, Table 1). This gas mixture shows that some form of unpurified reformer gas could be used to reduce the ferric iron in this electrolyte solution. In these runs, the liquid flow rate had a more pronounced effect on increasing the ferric reduction rate, consistent with a shift of the rate-limiting step back to mass transfer as the hydrogen led to faster kinetics on the catalyst.

\subsubsection{Methane}

Runs with pure methane gas were expected to show little or no reduction in the ferric iron because of the stability of the C-H bonds in that molecule. The actual performance however is unusual (Figures 9-10). The runs in these figures are listed in the same order that they were performed. Five nominally identical runs, labeled a-e in Figure 9, showed a large initial increase in ferric concentration in the first two runs, followed by two runs with a slow decrease, ending with a run with a small decrease. The next two runs at higher liquid circulation rates both had increases in the ferric concentration. The increases all stop at $6 \mathrm{~g} / \mathrm{L}$ because that value corresponds to the highest absorbance measurable by the spectrophotometer. The two runs with platinum catalyst did something similar (Figure 10). These results suggest that methane might 
be able to reduce ferric to ferrous ion. They are also indicative of an interfering reaction of either air, sulfate, or other oxidant in this system. The fact that the results vary significantly between runs suggests that the interfering agent is air rather than sulfate, which was present at a fixed concentration.

\subsubsection{Nitrogen}

Nitrogen was also expected to be inert, causing very little or no reduction of the ferric iron. However, the nitrogen runs (Figures 11-12) showed changing results similar to the methane runs. With the platinum catalyst, ferric reduction occurred in the first two nitrogen runs which happened to be the first use of that catalyst. Platinum catalyst on carbon is made by using hydrogen gas to reduce a mixture of platinum chloride, hydrochloric acid and water to the zero valent metal (3). Palladium on carbon is made similarly. Presumably hydrogen was still absorbed onto the catalyst from this reduction process, allowing ferric ion reduction to occur even though the reactor was purged with nitrogen for twenty minutes before the first run. After those first two runs no ferric ion reduction occurred, as expected. With the palladium catalyst, a similar explanation applies only in this case the hydrogen was thought to be left over from previous runs in these experiments rather than from the catalyst manufacturing.

\subsection{Catalysis Using Graphite}

To expand upon earlier results showing that 200 mesh carbon particles could catalyze ferric ion reduction by hydrogen $(1,2)$, the trickle bed reactor was filled with graphite rods cut to pieces $1 / 4$ " long. Electrolyte solution was circulated at 70 and $140 \mathrm{ml} / \mathrm{min}$ while hydrogen flow was constant at $180 \mathrm{ml} / \mathrm{min}$. These conditions were also used in the majority of other experiments (gas and catalyst type). Very little if any ferric reduction occurred. A third run repeated the second set of conditions except that $1.0 \mathrm{~g} / \mathrm{L}$ of $\mathrm{PdCl}_{2}$ was added to the initial electrolyte solution to attempt to deposit Pd metal onto the carbon when hydrogen was added. When it was added while making up the electrolyte, the solution turned green, and when the $\mathrm{FeSO}_{4}$ was subsequently added a black precipitate formed. This was likely caused by the reduction of $\mathrm{Pd}^{2+}$ to $\mathrm{Pd}$ metal coupled to the oxidation of the added $\mathrm{Fe}^{2+}$ to $\mathrm{Fe}^{3+}$. Reduction of ferric ion in this solution occurred at a very low rate. It is possible that the graphite rods used in all these runs were inactive because they had little surface area compared to material prepared as a sorbent or catalyst support, or possibly the previous results might have been artifactual.

\subsection{Catalysis Using Copper Turnings}

By using copper turnings as the reducing agent, it was hoped to eliminate the use of precious metal catalysts. The sequence of reactions is the copper turnings reduce ferric ion to ferrous ion and then the hydrogen (or other reducing gas) reduces $\mathrm{Cu}^{2+}$ back to $\mathrm{Cu}^{0}$. The overall reaction is thus the reduction of ferric ion to ferrous ion with the $\mathrm{Cu}^{0} / \mathrm{Cu}^{2+}$ reaction as an electron shuttle.

The trickle bed reactor was packed with 55 grams of copper turnings. Electrolyte solution was circulated at $34 \mathrm{ml} / \mathrm{min}$ while hydrogen flow was constant at $37 \mathrm{ml} / \mathrm{min}$. After three hours the flow of hydrogen and solution were stopped and the column was disassembled. The copper turnings were washed four times with deionized water, then three times with acetone, dried under nitrogen overnight, and weighed.

Ferric ion solution was reduced to ferrous ion in this trial, but an amount of copper turnings equivalent to the amount of ferric ion reduced was dissolved. To reduce the 1.5 grams per liter of $\mathrm{Fe} 3+$ ion in solution would require 0.8534 grams $\mathrm{Cu}^{0}$ if the hydrogen gas did not reduce any $\mathrm{Cu}^{2+}$ to $\mathrm{Cu}^{0}$. The actual amount of copper dissolved from the turnings was 0.8778 grams. Thus, within experimental error, the hydrogen gas failed to reduce $\mathrm{Cu}^{2+}$ back to $\mathrm{Cu}^{0}$. For hydrogen to reduce ferric ion to ferrous ion, the hydrogen must be activated by a better catalyst. Copper metal by itself is not active enough. 


\section{DISCUSSION}

The basic concept that hydrogen can be used to reduce ferric ion back to ferrous ion for recycling to a copper electrowinning process has been shown to work. Further, carbon monoxide, a byproduct of the production of hydrogen, can also reduce ferric ion although the rates are slower.

The experiments with hydrogen were limited by the rate of hydrogen mass transfer into the liquid electrolyte. This system was not designed to maximize that rate, although the general configuration of a trickle bed reactor is good for promoting gas-liquid contacting. Because the reactor and catalyst size combination used here flooded at high liquid rates, designing them to accommodate even higher liquid rate would be expected to give even higher reduction rates. In addition, the use of even modest positive pressure in the reactor would provide a significant percentage increase in the hydrogen's partial pressure, boosting the mass transfer rate a corresponding amount. While not especially feasible in glassware, this could be done simply in an industrial system.

Although these tests were intended only to measure reaction rates, they also showed no problems with precipitation of solids or foaming, two potential difficulties in operating a trickle bed system.

\section{RECOMMENDATIONS}

A. Laboratory testing should be continued to identify better catalysts for hydrogen and carbon monoxide usage. They may be different catalysts for each gas. Because of its ready availability as natural gas, methane should be retested at least briefly. Finely divided graphite particles should be tested again because of their lower cost and good performance in earlier work, even though large graphite pieces did not work here. These tests must be set up so that (1) air is carefully excluded from the system between runs and (2) mass transfer effects are minimized while collecting the catalyst kinetics data.

B. The conceptual design of a full scale reactor should be started. This includes evaluating other reactor configurations and calculating the maximum gas transfer rate that can be expected from each design.

C. A preliminary process flow sheet with a complete material balance on all the reactants should be developed to guide further testing. This flow sheet should estimate the necessary equipment sizes, including ancillary equipment such as compressors and liquid circulation pumps and reservoirs.

D. Building on the previous task, preliminary estimates of equipment and operating costs should be worked up for the alternative flow sheets. The most promising should receive further laboratory and design attention. In particular, alternative systems for bringing in bulk hydrogen by trailer or instead creating it on-site via reforming of natural gas should be compared.

E. Because carbon monoxide reacts about an order of magnitude slower than hydrogen (at least in these tests), if on-site reforming appears attractive there should be a near term project goal to evaluate whether it is preferable to use the carbon monoxide to reduce ferric ion directly or instead to use it to generate additional hydrogen via the commonly used water-gas shift reaction

$$
\mathrm{CO}+\mathrm{H}_{2} \mathrm{O} \rightarrow \mathrm{CO}_{2}+\mathrm{H}_{2}
$$




\section{REFERENCES}

1. J. D. Miller, M. L. Free, and J. B. Hiskey, Alternative Anode Reaction Project (Bechtel Contract \#00009228), Final Report

2. J. D. Miller, M. L. Free, and J. B. Hiskey, Alternative Anode Reaction Project Report Summary

3. Palladium/Platinum Catalyst Preparation FAQ, Organic Syntheses, Collective Volume \#, p. 685 (1955); http://chem;labs1.tripod.com/chemistry/pd-catalyst.faq.html 


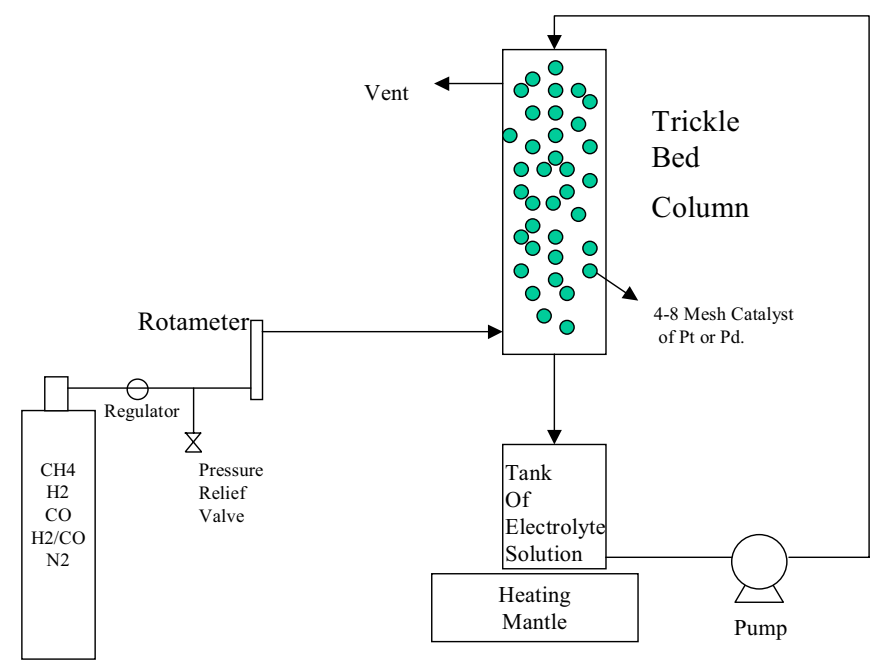

Figure 1 Schematic of Trickle Bed Setup

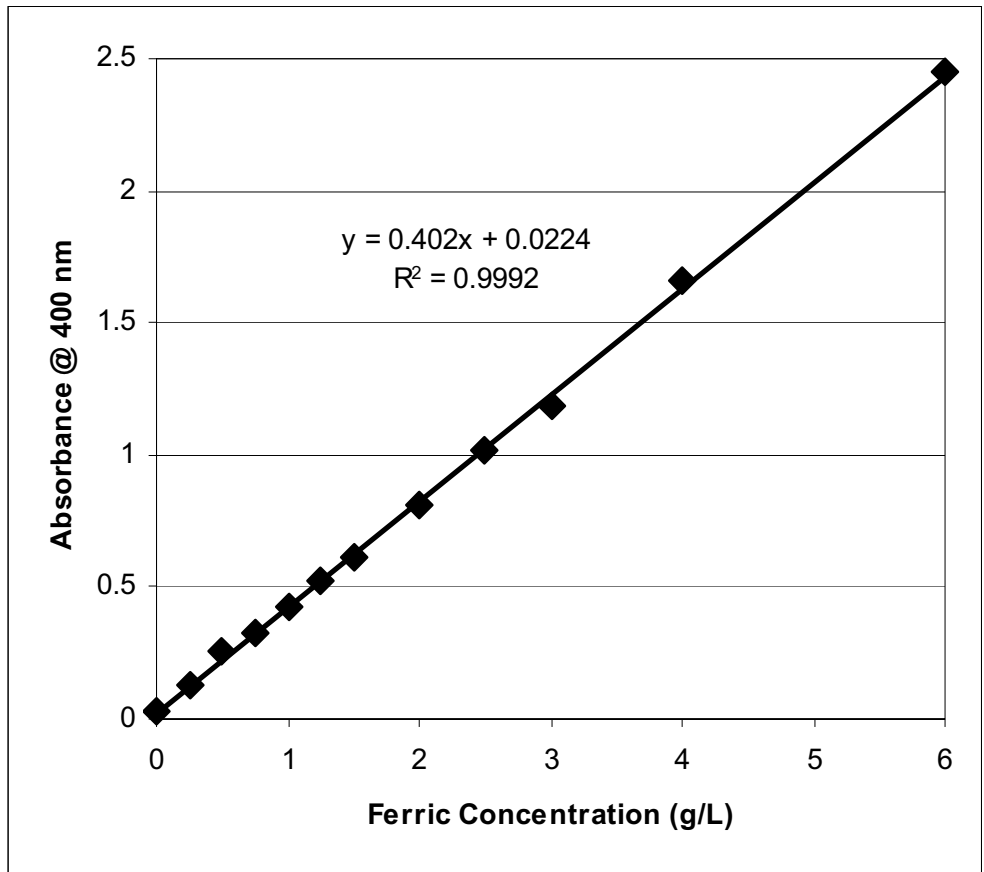

Figure 2 Standard Curve for Ferric Ion Concentration vs Absorbance at $400 \mathrm{~nm}$ 


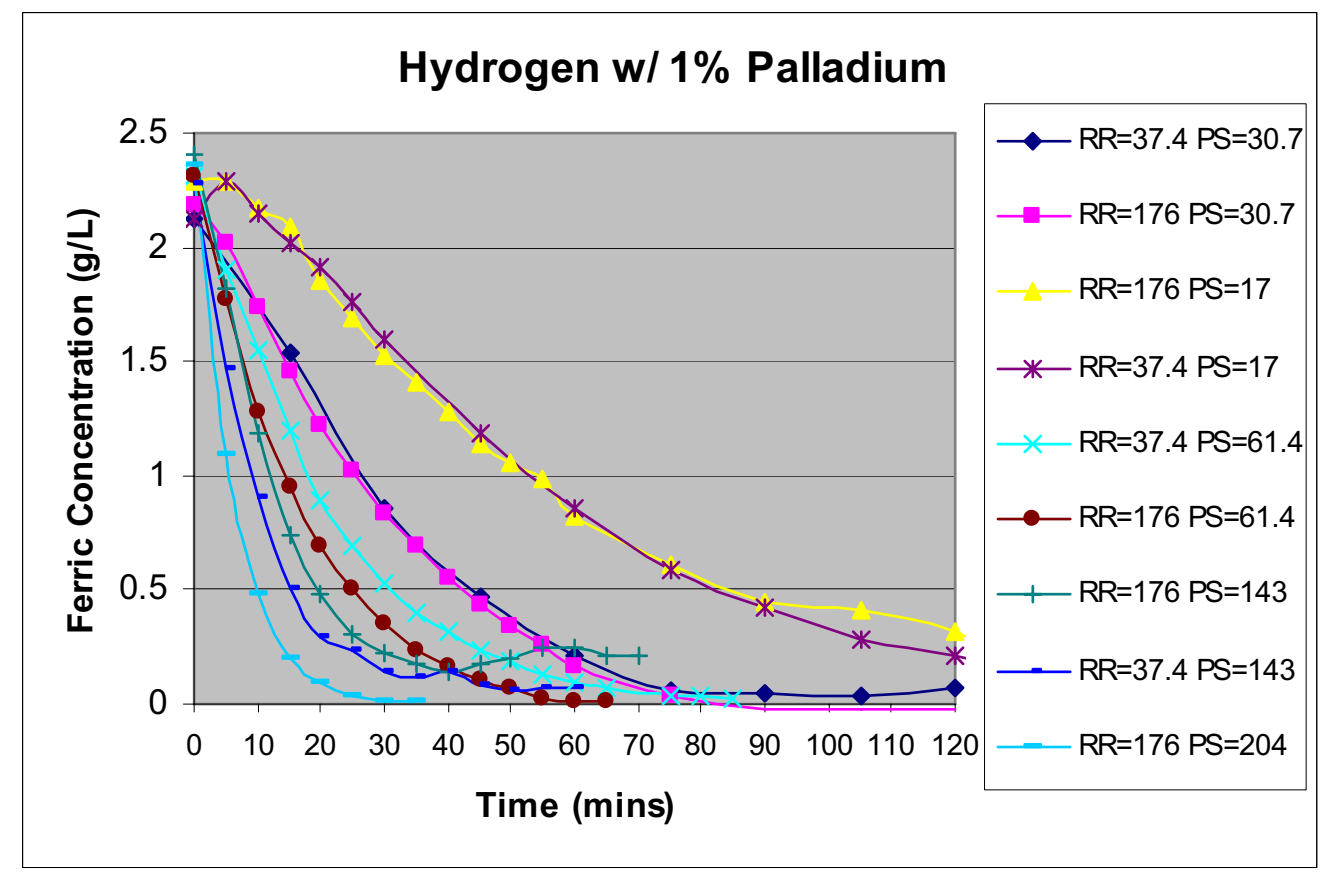

Figure 3 Hydrogen on Palladium

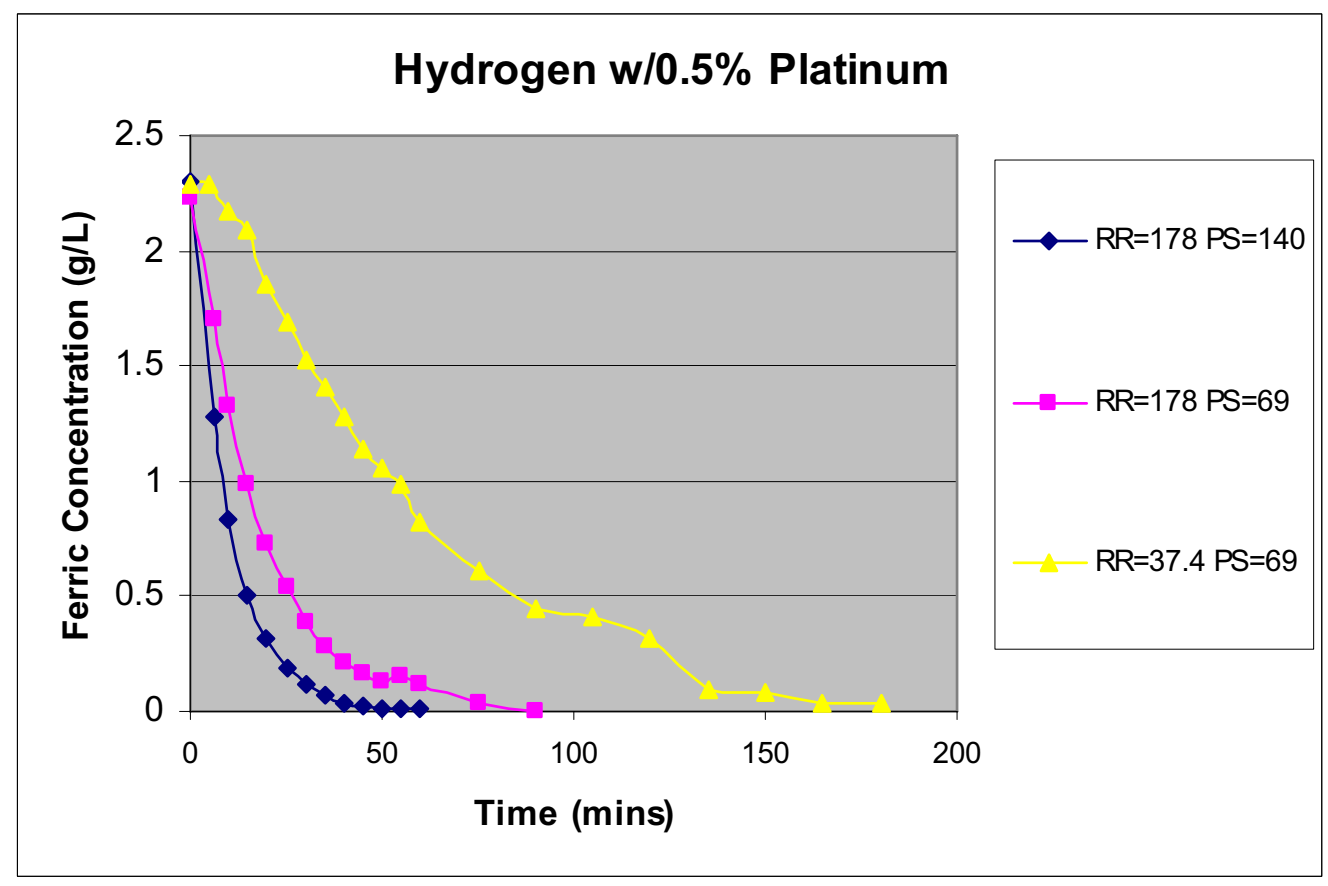

Figure 4 Hydrogen on Platinum 


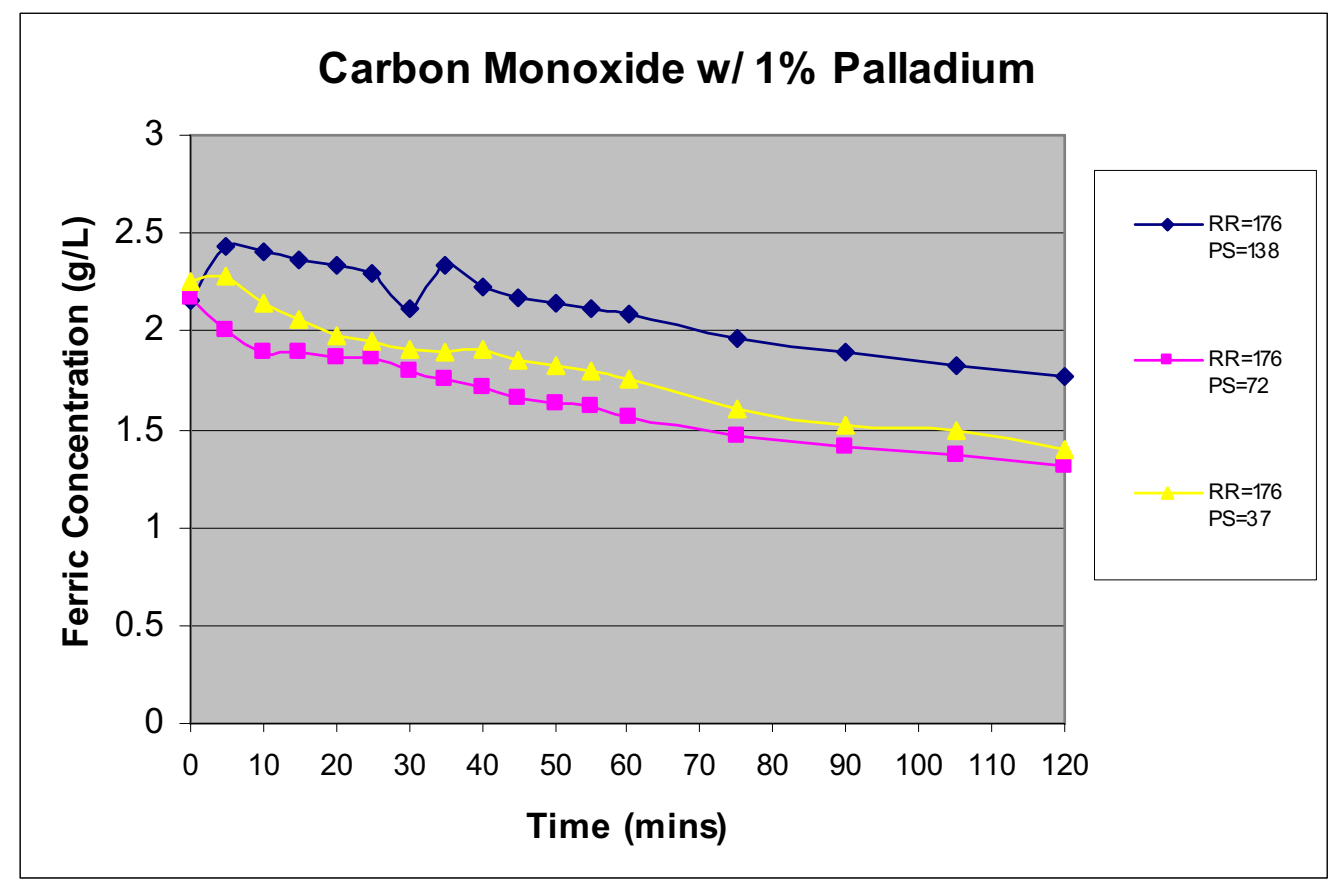

Figure 5 Carbon Monoxide on Palladium

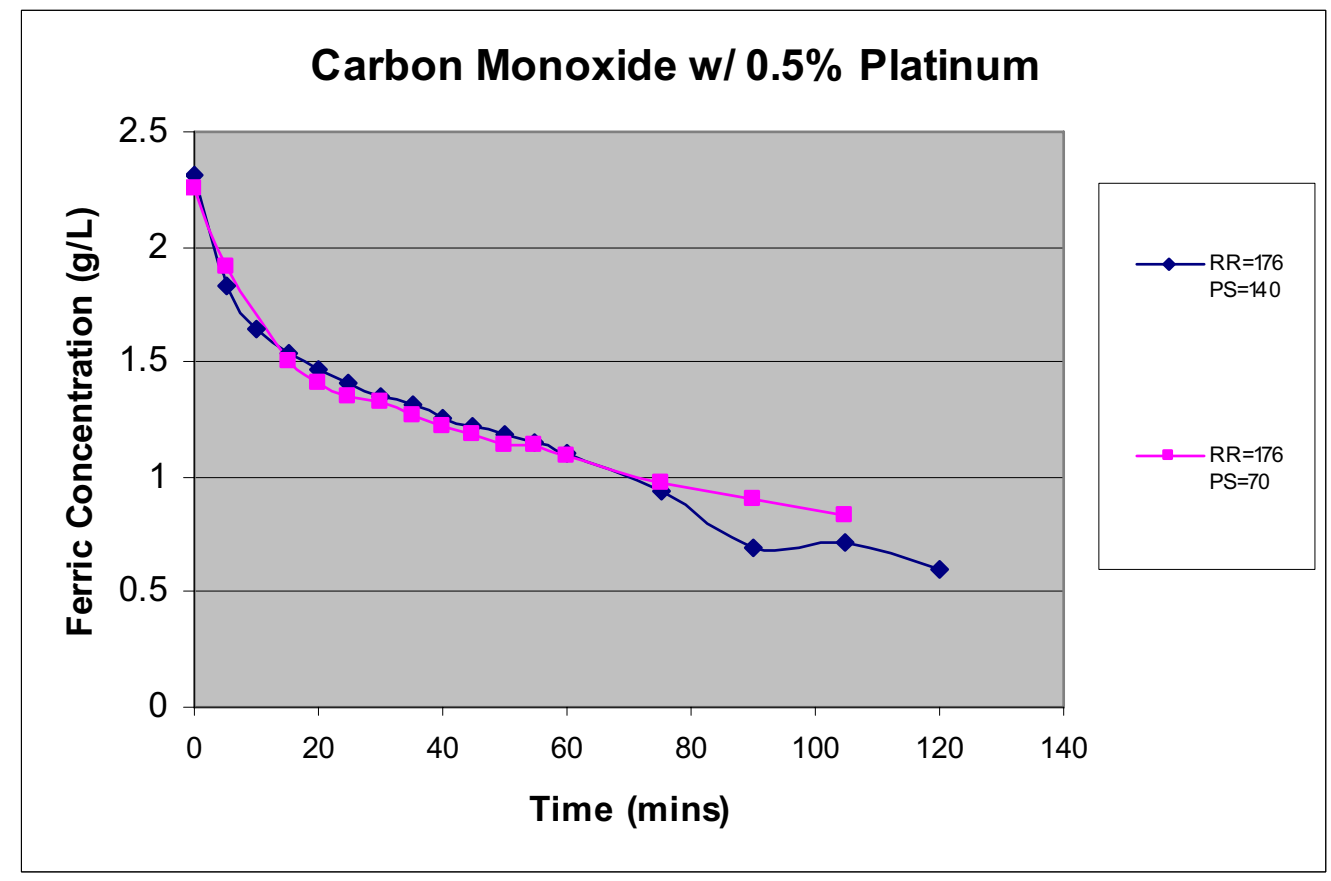

Figure 6 Carbon Monoxide on Platinum 




Figure 7 Hydrogen/Carbon Monoxide on Palladium



Figure 8 Hydrogen/Carbon Monoxide on Platinum 


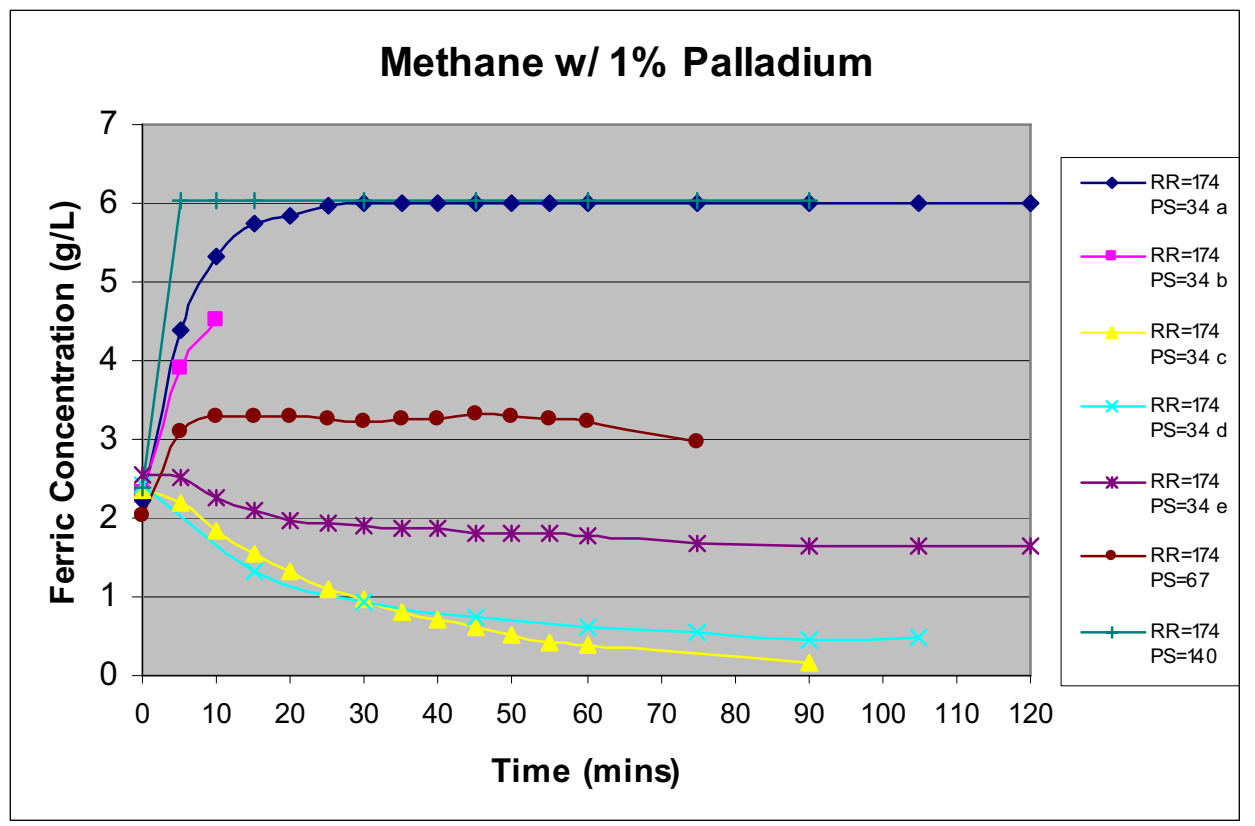

Figure 9 Methane on Palladium

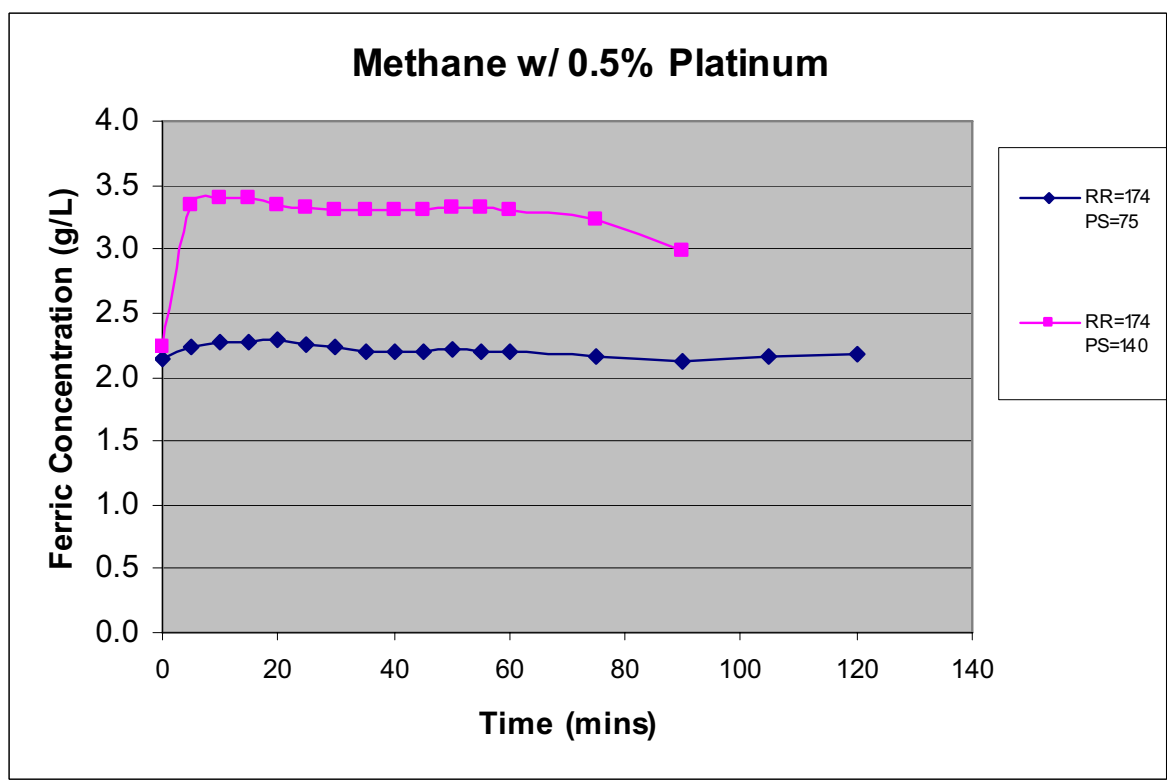

Figure 10 Methane on Platinum 


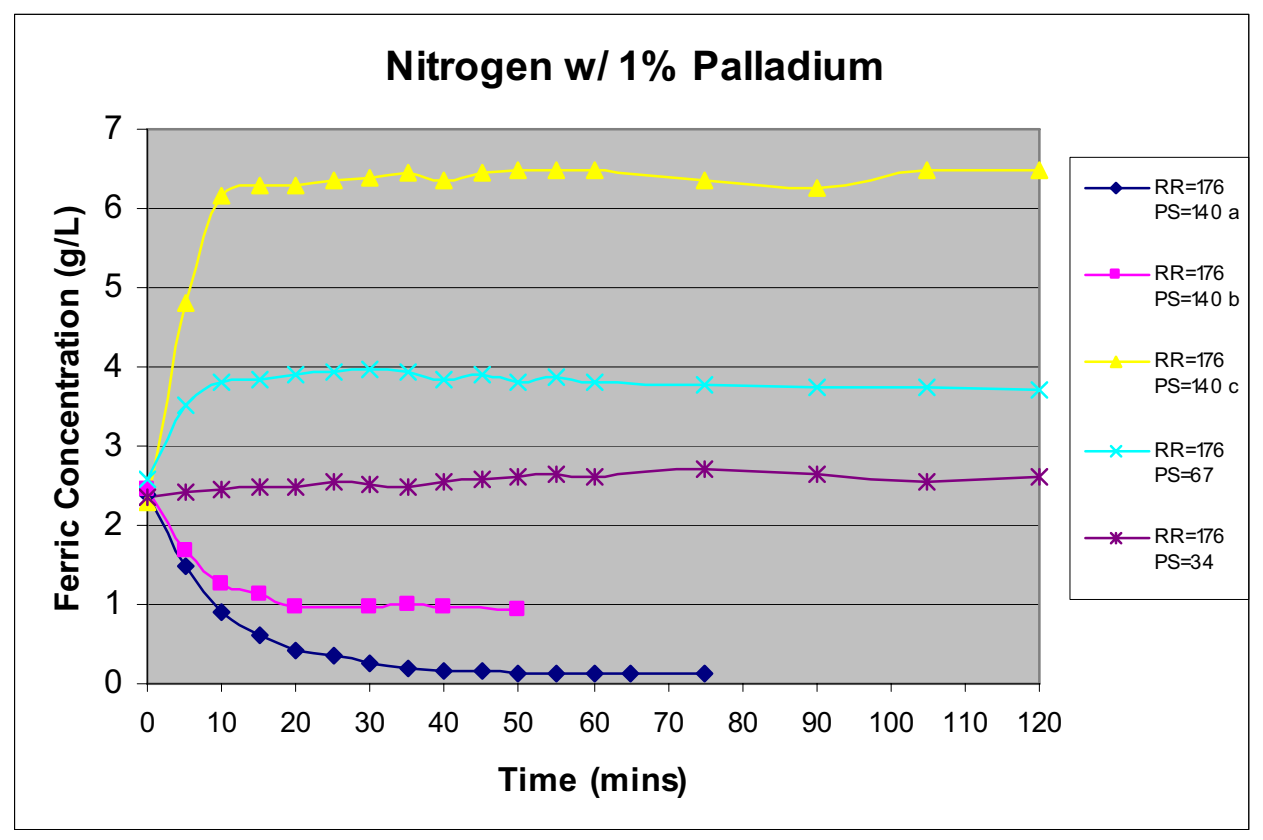

Figure 11 Nitrogen on Palladium

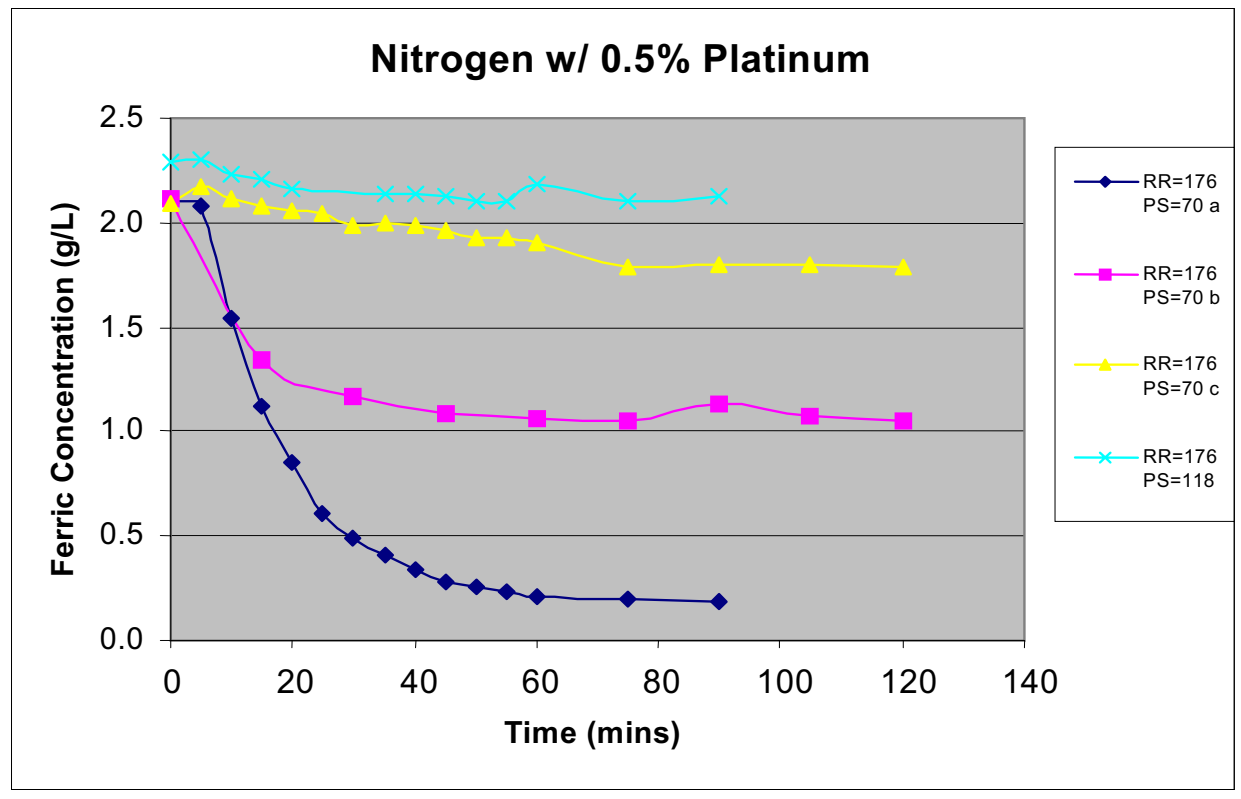

Figure 12 Nitrogen on Platinum 
Table 1 Ferric Ion Reduction Rates

\begin{tabular}{|c|c|c|c|c|}
\hline Gas & $\begin{array}{r}\text { Gas Flow } \\
(\mathrm{ml} / \mathrm{min})\end{array}$ & $\begin{array}{l}\text { Liquid Flow } \\
(\mathrm{ml} / \mathrm{min})\end{array}$ & Catalyst & $\begin{array}{c}\text { Reduction Rate } \\
(\mathrm{g} / \mathrm{L} / \mathrm{min})\end{array}$ \\
\hline $\mathrm{H}_{2}$ & 37 & 17 & $\mathrm{Pd}$ & 0.0231 \\
\hline $\mathrm{H}_{2}$ & 176 & 17 & $\mathrm{Pd}$ & 0.0272 \\
\hline $\mathrm{H}_{2}$ & 37 & 31 & $\mathrm{Pd}$ & 0.0375 \\
\hline $\mathrm{H}_{2}$ & 176 & 31 & $\mathrm{Pd}$ & 0.0405 \\
\hline $\mathrm{H}_{2}$ & 37 & 62 & $\mathrm{Pd}$ & 0.0656 \\
\hline $\mathrm{H}_{2}$ & 176 & 62 & $\mathrm{Pd}$ & 0.0668 \\
\hline $\mathrm{H}_{2}$ & 37 & 143 & $\mathrm{Pd}$ & 0.118 \\
\hline $\mathrm{H}_{2}$ & 176 & 143 & $\mathrm{Pd}$ & 0.113 \\
\hline $\mathrm{H}_{2}$ & 176 & 204 & $\mathrm{Pd}$ & 0.1881 \\
\hline $\mathrm{CO}$ & 174 & 37 & $\mathrm{Pd}$ & 0.0071 \\
\hline $\mathrm{CO}$ & 176 & 72 & $\mathrm{Pd}$ & 0.0084 \\
\hline $\mathrm{CO}$ & 176 & 138 & $\mathrm{Pd}$ & 0.0072 \\
\hline $\mathrm{H}_{2} / \mathrm{CO}$ & 37 & 37 & $\mathrm{Pd}$ & 0.0251 \\
\hline $\mathrm{H}_{2} / \mathrm{CO}$ & 37 & 133 & $\mathrm{Pd}$ & 0.0606 \\
\hline $\mathrm{H}_{2} / \mathrm{CO}$ & 176 & 70 & $\mathrm{Pd}$ & 0.0228 \\
\hline $\mathrm{H}_{2} / \mathrm{CO}$ & 176 & 71 & $\mathrm{Pd}$ & 0.0229 \\
\hline $\mathrm{H}_{2} / \mathrm{CO}$ & 176 & 128 & $\mathrm{Pd}$ & 0.069 \\
\hline $\mathrm{H}_{2}$ & 37 & 17 & $\mathrm{Pt}$ & 0.0264 \\
\hline $\mathrm{H}_{2}$ & 178 & 69 & $\mathrm{Pt}$ & 0.0758 \\
\hline $\mathrm{H}_{2}$ & 178 & 140 & $\mathrm{Pt}$ & 0.0975 \\
\hline $\mathrm{CO}$ & 176 & 70 & $\mathrm{Pt}$ & 0.0071 \\
\hline $\mathrm{CO}$ & 176 & 140 & $\mathrm{Pt}$ & 0.0101 \\
\hline $\mathrm{H}_{2} / \mathrm{CO}$ & 37 & 69 & $\mathrm{Pt}$ & 0.0103 \\
\hline $\mathrm{H}_{2} / \mathrm{CO}$ & 176 & 69 & $\mathrm{Pt}$ & 0.0383 \\
\hline $\mathrm{H}_{2} / \mathrm{CO}$ & 176 & 138 & $\mathrm{Pt}$ & 0.0536 \\
\hline
\end{tabular}

